\title{
Modelling Delay of Road Construction Projects in 'No Funding- Stress' Scenario using Ordinal Logistic Regression Approach
}

\author{
Scholastica F. Ekanem ${ }^{1 *}$ Godwin O. Jagboro ${ }^{2}$ Akintayo Opawole ${ }^{2}$ Timothy O. Adewuyi ${ }^{3}$ \\ 1. Department of Quantity Surveying, Akwa Ibom State Polytechnic, Ikot Osurua, \\ Akwa Ibom State, Nigeria \\ 2. Department of Quantity Surveying, Obafemi Awolowo University, Ile-Ife, Osun State, Nigeria \\ 3. Department of Building, University of Uyo, Uyo, Akwa Ibom State, Nigeria
}

\begin{abstract}
The study examined critical delay causative factors impacting the delivery of road projects in 'no funding stress' scenario and modelled the variables as a procedural step towards capturing and managing their occurrence in such a scenario. The study adopted a quantitative descriptive approach, which was based on a questionnaire survey. A total of thirty-six organisations that were involved in the Niger Delta Development Commission (NDDC) road projects in the Niger Delta Region of Nigeria constituted the study population. These were distributed as; 8 client organisations, 13 consulting organisations, and 15 contracting organisations. A total enumeration of the 36 organizations enabled 153 professionals distributed as; 33 quantity surveyors and 120 civil/structural engineers to be sampled. Inferential statistics, rating weighted agreement (RWA), and impact weighting (IW) were employed to isolate the critical factors. Ordinal logistic regression (OLR) was used to model the delay, which was validated using a split-quarter cross-validation method. Twenty-nine critical causative factors were derived with the top three as; mobilization delay, interference by political leader, and high rate of inflation. Ordinary Logistic Regression enabled 11 variables, which had Wald's statistic significant at a $p$-value $\leq 0.25$ to be selected among the 29 critical causative factors for developing a model that predicts project delay quantum in 'no funding stress' scenario. The study provided implications both for project management and government policy development. In the first place, empirical evidence provided is suitable for managing road project delivery in a 'no funding stress' scenario through the development of metrics for improvement of time performance. Most importantly, the study modelled the time variables in this scenario to assist in predicting project delay quantum from inception. The findings also provide implications for government policy response, which would guide the delivery of regional intervention projects. Empirical evidence is provided on road project delivery with special funding intervention that results in a 'no funding stress' scenario. Modelling delay occurrence in such a scenario extends the quantitative approach to the body of knowledge on time performance management in road project delivery.
\end{abstract}

Keywords: Critical impact factors, delay, Niger Delta Region, ordinal logistic regression, Pareto principle, road construction projects.

DOI: $10.7176 /$ CER/12-9-07

Publication date:September 30th 2020

\section{Introduction}

Road construction is one of the cardinal investments that are meant to bring about growth and development in every nation, as it provides access to many socio-economic activities. Road construction is characterised by complexities in the procedure, which is defined by many stakeholders; the client, project managers, construction professionals, material traders, and users, among others, that are involved (Divya \& Ramya, 2015). Mulla and Waghmare (2015) asserted that it is difficult for a road project to be completed within the projected cost, stipulated duration, and with the anticipated quality demanded by clients as a consequence of delays. Despite new inventions and highly developed technologies, the parties' contributions and recurrent client-desired changes, the construction industry's inherent qualms and convolutions in the face of socio-economic and environmental factors in which most projects are executed are making the completion of road projects within the planned time a complicated task to achieve (Mulla \& Waghmare, 2015). Consequently, the issue of construction delay has assumed a grave disquiet to the participants in the construction environment. Shahid et al. (2015) established that delays are the major sources of disputes confronting the construction industry. The level of delays and how the causative factors influence project performance are becoming frightening and disturbing, thus demanding a pragmatic investigation.

Delays in road construction projects remain a major object of disapproval in the construction industry such that scholars' attention has been drawn to it from different parts of the world such as Hong Kong, Jordan, Malaysia, Saudi Arabia and Thailand (Al-Kharashi \& Skitmore, 2009; Al-Momani, 2000; Simon, 2017). Opinions from researchers reveal similarities and dissimilarities as to what constitutes the root causes and effects of delay 
depending on location and execution time. Meanwhile, several attempts by construction professionals and researchers to tackle the causes and effects of delay in road projects have not yielded sufficient positive results in developing countries. Emerging facts revealed that recent technology and improved expertise have not been able to prevent delay of road construction projects, so completion dates still suffer setbacks (Ekanem, 2019).

This study attempts to study delay in a special scenario where time performance is influenced by factors other than funding, described as 'no funding stress' scenario in this study, using a case study of Niger Delta Development Commission (NDDC) road projects. The Federal Government established the Niger Delta Development Commission (NDDC) in response to the agitations from the Niger Delta region of Nigeria due mainly to environmental degradation ensuing from oil exploration activities in the area. Despite the region's highest contributions to Nigeria's wealth, the development of road projects in the region remain very stunted (Aybu, 2005; Jike, 2005). The logic of recurrent agitations, hostility, and militia movements originate from the persistent deprivation of people in the region in terms of infrastructural development. Moreover, during various constitutional conferences before 1960, when Britain officially approved Nigeria's independence, the Niger Delta region was recognised as an area for special development. The Nigerian constitution, at that time, spelt out $50 \%$ of the royalty resulting from oil and gas exploration to the region where the oil was drilled. This was the principle standard approved after the Nigerian civil war (1967-1970). Upon the establishment of NDDC, several road projects were commissioned to address under-developmental challenges in the region. These projects were funded by $13 \%$ of Nigeria's federation account, which provided surplus funding for road projects in the region (Dafinone, 2007).

Despite the huge capital available to road projects, through the NDDC, many road projects that were awarded since 2000 have not achieved acceptable performance as most of the contracts are either not commenced, partially completed, or in some cases, were totally abandoned (Isidiho \& Sabran, 2015). This situation raises the questions of characteristics of regional intervention road projects in 'no funding stress' scenario, most especially, what is the level of delay in this scenario? What are the factors influencing the delay of road projects in the 'no funding stress' scenario? How does delay impact on completion time in this type of scenario? With virtually no empirical evidence of the management of delay of road projects in this scenario in the Nigerian construction industry, this study aims to evaluate road project delivery in 'no funding stress' special intervention scenario with a view to developing metrics for time performance of road projects.

The study is expected to provide implications for the execution of special regional intervention road projects, especially in the construction industry, with similar socio-political, environmental, and economic climates to the Niger Delta region. Most importantly, the study attempts to model the time variables in this scenario that could assist in predicting possible delay occurrence and install adequate planning techniques at the project inception. The overall findings of the study are expected to provide implications for policy response, which would guide the delivery of regional intervention projects.

\section{Theoretical and Literature Review}

Delay as a product of poor performance of a construction project's time objective has attracted many studies (AlKharashi and Skitmore, 2009; Al-Momani, 2000). According to Enshassi, Mohamed and Abushaban (2009), delay in the completion of construction projects remains an area of criticism in the global context. Delay, essentially can be viewed as the time lag between the final and initial completion time prescribed at the commencement of construction work. Shahsavand et al. (2018) described delay in construction as the extra plan performed either beyond completion date specified or beyond the date that was agreed by the parties in the signed document for delivery of the project. The assertion of Sunjka and Jacob (2013) that construction delay is an occurrence that is universal in the life of every project with the levels and causative factors differing from project to project and from region to region suggests a possible variation of causative delay factors in different region context.

Findings of earlier studies have revealed similarities and dissimilarities as to what constitutes the root causes of delay and their effects depending on location and execution time. Meanwhile, existing studies on the causes and effects of delay of road projects appeared not to have yielded sufficient positive results in developing countries. Even with recent technology, and managerial techniques, road projects still suffer from delay, and completion dates get pushed forward (Aibinu \& Odeyinka, 2006). Kikwasi (2012), for example, opined that delays occur in road construction projects as a result of the parties involved regarding road projects merely as linear and straight-line projects with no adequate planning attached at the inception. The work of Assaf and Al-Hajji (2006) revealed that about $70 \%$ of road construction projects experienced averagely $10 \%-30 \%$ of the time overrun of the original contract duration. Similar assessment by Opawole (2015) on project time performance using institutional building projects in selected Nigerian Universities as a case study revealed time overrun ranging from $27-333 \%$ as a result of insufficient cash flows. However, the findings of these studies may not be generalised based on two major reasons. Firstly, Opawole (2015) focused essentially on building projects while Assaf and Al-Hajji (2006) captured 
only contractors', consultants', and clients' perceptions, excluding other stakeholders' views. Secondly, environmental conditions that are highly significant in NDDC road projects may limit the comparison of the level of delay in the two cases and most of the earlier studies to the road projects in the Niger Delta region.

Sambasivan and Soon (2007) revealed inadequate planning, inadequate managerial skills, cash flow problem, shortage in materials, shortage of labour supply, unavailability of equipment and failure on its delivery to site, lack of communication among the parties, and mistakes during the construction stage as significant causative factors of delay in the construction industry in Malaysia. The finding also identified major effects as a result of delays such as; cost overrun, disputes, lawsuit, and total desertion of the project. Haseeb, Xinhai-Lu, Bibi, Maloofud and Rabbani (2011) highlighted the factors contributing to delay to include; natural tragedy, monetary problems, inadequate preparation, ineffective management on site, inexperienced personnel, poor method of procurement, and environmental nuisance. Kikwasi (2012) opined that delays occur in road construction projects as a result of the parties involved regarding road projects merely as linear and straight-line projects with no adequate planning attached at the inception. In Abdullah (2013), in-house administration problems, delayed payment for completed works, poor communication networks among construction teams, and slow decision-making were identified as the key delay causative factors. Mwawasi (2015) identified alteration in the scope of work, inconsistencies in the bill of quantities and design document, delay of payment for completed works, lack of monitoring and supervision, fluctuations in materials prices, and unpredictable weather as the major delay factors. Meanwhile, in the assessment of contractors' and consultants' perceptions of delay in construction projects in Pakistan, Zafrullah (2016) identified the delay causative factors as; subcontractors' delay and change of orders by clients during project execution, in addition to those earlier identified by Mwawasi (2015). Funding for road development in the Niger Delta communities presents a model for studying delay causative factors in typical 'no funding stress' scenario. This is because the capital allocation of $13 \%$ intervention from Nigeria's federation account is available to the region for infrastructure development (Dafinone, 2007). Practical evidence of the management of delay in this scenario in project delivery seems not readily available. This has made it impossible to develop acceptable metrics for time performance in such a scenario. Alphonsus and Mohammed (2015) opined that the performance of project objectives in NDDC road projects is generating a negative impact on socio-economic activities in the region. The delivery of road projects in Niger Delta has been observed with peculiarities regarding the climatic condition, socio-political and economic problems Odesola (2012).

Empirical shreds of evidence are not readily available on time performance of road projects characterized by such special regional projects with almost 'no funding stress' scenario. The 'no funding stress' of NDDC road projects is indicated by the $13 \%$ intervention from Nigeria's federation account, which provided surplus funding for road projects in the Niger Delta region (Dafinone, 2007). This does not, however, preclude the influence of bureaucratic bottlenecks and corrupt practices associated with the release of funds in the delivery of the projects. This study has become imperative to provide implications for the development of acceptable metrics for their time performance. Moreover, knowledge of the level of delay, as well as their relative impact on final contract duration, would be valuable in modelling the time variables in this scenario that could assist in predicting possible delay occurrence and install adequate planning technique at the project inception.

\section{Methodology}

The study adopted a quantitative descriptive approach, which was based on a questionnaire survey. A total of thirtysix firms/organisations that were involved in the Niger Delta Development Commission (NDDC) road projects in Nigeria constituted the study population. These organisations were distributed as; 8 client organisations, 13 consulting organisations, and 15 contracting organisations. A total enumeration of the 36 organizations enabled 153 professionals represented by the organisations as; 33 quantity surveyors and 120 civil/structural engineers to be sampled. Leedy and Ormord (2010) had considered a total enumeration of a study population as appropriate for a unit of analysis that is less than one hundred (100). The survey was carried out with the aid of a structured questionnaire since the study was based on an exploration of the perceptions of respondents on variables that are mostly measured in the ordinal scale. According to Kothari (2004), a closed-ended structured questionnaire are easy to answer and relatively quick to analyze. The questionnaire was segmented into two parts (A and B). Section A elicited information about the respondent's profile, such as; the academic qualifications and professional affiliations, and to enhance the reliability of the derived data. Section B sourced data on the specific purpose of the study. Five-point Likert scale ratings of 1 to 5 were assigned to the respondent's ratings of the variables, with 1 and 5 interpreted as lowest and highest point, respectively. The criterion-related reliability test of the questionnaire was measured using Cronbach's alpha. The coefficient was satisfactory at $0.886 \leq \alpha \leq 0.969$, for the factors. Hair, Anderson, Tatham and Black (2006) had postulated a lower limit of 0.6 as satisfactory to consider a research instrument as reliable. 
To determine the factors with critical impact on delay, the analysis was carried out using inter-rater agreement (IRA) scoring, as indicated in Equation 1. Estimates of IRA were used mainly to verify whether rating provided by a respondent is interchangeable or equivalent in complete terms, meaning that IRA is a perfectly reasonable technique for estimating raters' similarity. IRA represented by $\boldsymbol{R} \boldsymbol{W} \boldsymbol{G}$ (rating weighted agreement) was calculated using Equations 1 and 2 as presented by LeBreton and Senter (2008):

where:

$$
R W G=1-\frac{S_{x}^{2}}{\sigma_{E}^{2}}
$$

$S_{z}^{2}=$ the observed variance on the variable $\mathrm{X}$;

$\sigma_{E}^{2}=$ the variance expected when there is a complete lack of agreement among the judges; and

$$
\sigma_{E}^{2}=\frac{A^{2}-1}{12}
$$

where:

$\mathrm{A}=$ number of response option in the scale;

$S_{x}^{2}=$ the observed variance.

Inter-rater analysis is interpreted based on LeBreton and Senter (2008) which denoted $0.00-0.30=$ lack of agreement; $0.31-0.50=$ weak agreement; $0.51-0.70=$ moderate agreement; $0.71-0.90=$ strong agreement; and $0.91-1.00=$ very strong agreement. The IRA is different from other critical index parameters in exploring consensus using the variance in respondents' judgment rather than mean score seen in others. In the second part of the analysis, establishing the degree of impact of each of the variables of the delay was done using the impact weighting (IW) method. According to Opawole and Jagboro (2016), the scale enabled the transformation of impacts of different variables of data into relative indices of the variable used by using numerical scores. The impact weighting formula was derived from the modification of relative importance index (RII) formula as presented in Equation 3, while the modified expression for deriving relative impact index of the individual variable is presented in Equation 4. The interpretation of the impact weighting (IW) is in percentages.

$$
I W=\frac{R I_{m} I}{\sum_{i}^{n} R I_{m} I}
$$

where:

IW = Impact Weighting;

$\mathrm{RI}_{\mathrm{m}} \mathrm{I}=$ Relative Impact Index of individual variable; and

$$
R I_{m} I=\frac{\sum_{1}^{5} n_{i} k_{i}}{N * R h}
$$

where:

$$
\begin{aligned}
& \mathrm{n}_{\mathrm{i}}=\text { number of respondents choosing ki; } \\
& \mathrm{k}_{\mathrm{i}}=\text { constants } 1-5 \text { (on Likert scale) with } 1=\text { lowest and } 5=\text { highest; } \\
& \mathrm{N} \quad=\text { Total number of questionnaires collected or analysed; and } \\
& \mathrm{Rh} \quad=\text { the highest value in rating order. }
\end{aligned}
$$

For the purpose of modeling the delay in road projects (the dependent variable of the study), the ordered ratings of the respondents to the factors impacting the level of delay in road projects were employed. The question "please tick $(\checkmark)$ as appropriate, based on your experience, the level of impact of the following factors on the delay of road projects procured by NDDC" formed the dependent variable. The five possible answers were; very little, little, moderate, long, and very long. Due to the type of answers to the question used as dependent variables, the choice of the econometric model adopted was the ordinal logistic regression or logit (Silva \& Nobre, 2018), given the fact that conventional estimation techniques (e.g., multiple regression analysis) in this context of a discrete dependent variable are not a valid option. On the one hand, the assumptions needed for hypothesis testing in conventional regression analysis are violated (it is unreasonable to assume, for instance, that the distribution of errors is normal). Moreover, many determinants can influence the delay of road projects that other conventional approaches could represent because some values cannot be converted into probabilities, which means they cannot be expressed in an interval between 1 and 5. Thus, the delay of road construction projects was estimated according to the logistic regression in Equation 5

$$
P(\text { Delay })=\frac{1}{1+\mathrm{e}^{-(\alpha+\beta x)}}
$$


where:

$$
\begin{aligned}
& P=\text { Probability of delay in completion; } \\
& \alpha=\text { Constant value in the categories; } \\
& \beta=\text { Variable coefficient; } \\
& x=\text { Variable (independent) value. }
\end{aligned}
$$

\section{Results and Discussion of Findings}

One hundred and thirty-eight (138) copies out of a total of 153 copies of the questionnaire administered were returned. Out of the 138 copies returned, 21 were rejected, as they were not correctly completed. The $117(76.47 \%)$ valid copies, which were adequately filled, provided quantitative data for this study. Analyses were run based on the objectives of the study, and the results were presented accordingly.

\subsection{Determination of Critical Factor of Delay in Road Construction Projects}

The critical factors of delay in road projects were spotted with the use of inter-rater formula as expressed in Equations 1and 2. The result, representing only the critical ones, of the descriptive analysis, is presented in Table 1, while the entire result is presented in Appendix 3. Interpretation is according to LeBreton and Senter (2008), as earlier discussed in this study. At the end of the analysis, only 29 variables were derived as critical ones based on the interpretation rule of $0.51 \leq \mathrm{x} \leq 1$ for moderate agreement and above. Kulemeka, Kululanga, and Morton (2015) observed that attempting to manage all identified important/significant variables simultaneously and giving them all equal attention is virtually impossible. However, by adopting the Pareto rule of separating out the important few from the trivial many to focus attention on the key variables, success is more likely. Therefore, the analysis of the critical factors was expected to identify the most significant variables that will adequately define or describe the causes of delay in road construction projects with respect to Pareto's principle. The Pareto principle (also known as the 80-20 rule) states that, for many events, roughly $80 \%$ of the effects come from $20 \%$ of the causes. Concomitantly, the number of variables derived could be explained by the Pareto principles, meaning that roughly $80 \%$ of the causes of delay could emanate from about $20 \%$, which most likely are to be the critical ones. In this view, the twenty-nine (29) variables represent about $22.14 \%$ of 131 identified factors that can impact on delay,

\begin{tabular}{|c|c|c|c|c|c|c|}
\hline Delay Factors Impacting on Project Performance & Sum & Mean & SD & Var & RWG & Decision \\
\hline Late procurement of materials & 381 & 3.256 & 0.82162 & 0.675 & 0.66 & MA \\
\hline Irregular attendant at site meeting & 324 & 2.769 & 0.87479 & 0.765 & 0.62 & MA \\
\hline Shortage of construction materials on site & 312 & 2.667 & 0.90019 & 0.810 & 0.59 & MA \\
\hline Late identification of errors and omissions in contract document & 340 & 2.906 & 0.91898 & 0.845 & 0.58 & MA \\
\hline Non-compliance to contract conditions & 362 & 3.094 & 0.92832 & 0.862 & 0.57 & MA \\
\hline Under estimation of materials & 301 & 2.573 & 0.93141 & 0.868 & 0.57 & MA \\
\hline Late drawing and specification delivery & 316 & 2.701 & 0.94015 & 0.884 & 0.56 & MA \\
\hline Inadequate feasibilities study & 345 & 2.949 & 0.95454 & 0.911 & 0.54 & MA \\
\hline Fluctuation in price of materials & 420 & 3.589 & 0.95731 & 0.916 & 0.54 & MA \\
\hline Interference by political leader (Government interest) & 454 & 3.880 & 0.95739 & 0.917 & 0.54 & MA \\
\hline Incompetent technical staff & 327 & 2.795 & 0.96077 & 0.923 & 0.54 & MA \\
\hline Unavailability of special equipment for special work & 305 & 2.607 & 0.96452 & 0.930 & 0.53 & MA \\
\hline Change in government regulation and market condition & 399 & 3.410 & 0.96627 & 0.934 & 0.53 & MA \\
\hline Incompetent foreman & 321 & 2.744 & 0.96627 & 0.934 & 0.53 & MA \\
\hline Poor materials management on site & 301 & 2.573 & 0.96772 & 0.936 & 0.53 & MA \\
\hline Lack of training of workers & 318 & 2.718 & 0.97243 & 0.946 & 0.53 & MA \\
\hline Mobilization delay & 478 & 4.085 & 0.97885 & 0.958 & 0.52 & MA \\
\hline Lack of skilled and unskilled site manpower & 323 & 2.761 & 0.97953 & 0.959 & 0.52 & MA \\
\hline Lateness to work by workers & 273 & 2.333 & 0.98261 & 0.966 & 0.52 & MA \\
\hline Change orders from client & 328 & 2.803 & 0.98470 & 0.970 & 0.52 & MA \\
\hline Rework due to changes ordered by the client or consultant. & 341 & 2.915 & 0.98762 & 0.975 & 0.51 & MA \\
\hline Lack of incentive to motivate work force & 324 & 2.769 & 0.99468 & 0.989 & 0.51 & MA \\
\hline Low quality/ standard of material supply & 327 & 2.795 & 0.99601 & 0.992 & 0.51 & MA \\
\hline Poor handing of materials & 308 & 2.633 & 0.99653 & 0.993 & 0.51 & MA \\
\hline Delay by sub-contractor's work & 330 & 2.821 & 0.99668 & 0.993 & 0.51 & MA \\
\hline High rate of inflation & 447 & 3.821 & 0.99668 & 0.993 & 0.51 & MA \\
\hline
\end{tabular}
which has fulfilled the Pareto principle, can adequately define the causes of delay in road construction projects in the study area.

Table 1: Critical Factors of Delay in Road Construction Project 


\begin{tabular}{|c|c|c|c|c|c|c|}
\hline Slow decision making & 326 & 2.786 & 0.99985 & 0.995 & 0.51 & MA \\
\hline Poor coordination of contract information & 325 & 2.778 & 0.99986 & 0.995 & 0.51 & MA \\
\hline Improper contract packaging/delivery & 331 & 2.829 & 0.99988 & 0.997 & 0.51 & MA \\
\hline
\end{tabular}

Having obtained the critical factors from inter-rater analysis, progress was made to evaluate their impact on delay using impact weighting (IW) analysis, as expressed in Equation 3. The relative impact indexes (RImI) of the individual variables were derived with the use of the expression in Equation 4. The result of the evaluation, in percentage, is presented in Table 2 .

The first five factors with the highest critical impact include mobilisation delay, interference by political leader (government interest), high rate of inflation, fluctuation in the price of materials and change in government regulation and market conditions with IW of $4.833 \%, 4.590 \%, 4.519 \%, 4.246 \%$, and $4.034 \%$, respectively. The study revealed that $4.833 \%$ of delay experienced in road construction projects is due to mobilisation. Meaning that delay in the mobilisation of a contractor to the site can have a significant influence on timely completion. Delay accruing from the mobilisation of a contractor may be attributed to bureaucratic bottleneck and misapplication/misappropriation of project funds. Mobilisation delay can prolong project duration, thereby resulting in poor time performance. Interference by political leaders is the second most critical factor that accounted for a $4.590 \%$ impact on delay in the study area. NDDC road construction projects suffered delay and timely completion as a result of the political leaders' personal interest, which is responsible for this factor, becoming a critical one. A high rate of inflation is responsible for $4.519 \%$ of delay. Fluctuation in prices of materials is another influential factor impacting on timely completion of road projects with $4.246 \%$ impact weighting. Both high rates of inflation fluctuation were significant to the contractors' organisations because most of the projects were not driven with adequate political will from the government. The factors were, however, not significant to government funding as the $13 \%$ crude oil sale derivative is on standby for the project financing.

Table 2: Impact Weightings of Critical Factors of Delaying Road Project

\begin{tabular}{lccc}
\hline Factors Impacting on Time Performance & $\mathbf{R I}_{\boldsymbol{m}} \mathbf{I}$ & $\mathbf{I W}$ & \%Impact \\
\hline Mobilization delay & 0.817 & 0.048 & 4.80 \\
Interference by political leader (Government interest) & 0.776 & 0.046 & 4.60 \\
High rate of inflation & 0.764 & 0.045 & 4.50 \\
Fluctuation in price of materials & 0.718 & 0.042 & 4.20 \\
Change in government regulation and market conditions & 0.682 & 0.040 & 4.00 \\
Noncompliance to contract conditions & 0.619 & 0.037 & 3.70 \\
Inadequate feasibilities study & 0.590 & 0.035 & 3.50 \\
Rework due to changes ordered by the client or consultant. & 0.583 & 0.034 & 3.40 \\
Late identification of errors and omissions in contract document & 0.581 & 0.034 & 3.40 \\
Improper contract packaging/delivery & 0.566 & 0.033 & 3.30 \\
Delay by sub-contractor's work & 0.564 & 0.033 & 3.30 \\
Change orders from client & 0.561 & 0.033 & 3.30 \\
Low quality/ standard of material supply & 0.559 & 0.033 & 3.30 \\
Incompetent technical staff & 0.559 & 0.033 & 3.30 \\
Slow decision making & 0.557 & 0.033 & 3.30 \\
Poor coordination of contract information & 0.556 & 0.033 & 3.30 \\
Lack of incentive to motivate the workforce & 0.554 & 0.033 & 3.30 \\
Irregular attendant at site meeting & 0.554 & 0.033 & 3.30 \\
Lack of skilled and unskilled site manpower & 0.552 & 0.033 & 3.30 \\
Incompetent foreman & 0.549 & 0.032 & 3.20 \\
Lack of training of workers & 0.544 & 0.032 & 3.20 \\
Late drawing and specification delivery & 0.540 & 0.032 & 3.20 \\
Shortage of construction materials on site & 0.533 & 0.032 & 3.20 \\
Poor handily of materials & 0.526 & 0.031 & 3.10 \\
Unavailability of special equipment for special work & 0.521 & 0.031 & 3.10 \\
Poor materials management on site & 0.515 & 0.030 & 3.00 \\
Under estimation of materials & 0.515 & 0.030 & 3.00 \\
Frequent site accident due to lack of health and safety measures & 0.487 & 0.029 & 2.90 \\
Lateness to work by workers & 0.467 & 0.028 & 2.80 \\
\hline & & &
\end{tabular}

These findings agreed with earlier studies like Thika. Elinwa and Buba (1994) and Stephen (2014). For example, 
Stephen (2014) revealed late procurement and delivery of materials to the site as a factor influencing the timely completion of power and lighting project in Thika. Elinwa and Buba (1994) had also indicated that fluctuation in materials prices and fraudulent practice among stakeholders are significant causes of delay that impact time performance in road construction projects. The analysis also showed that change in government regulation and market conditions with a $4.06 \%$ weighted impact as one of the most influential factors of delay that can have an impact on the execution of road construction projects in the study area. Other factors include none compliance to contract conditions with IW of $3.660 \%$, inadequate feasibilities study (IW $=3.488 \%$ ), and rework due to changes ordered by client or consultant with IW $=3.448 \%$. These factors revealed that, if properly managed during the execution of road construction projects, reduction in delay can be achieved.

Factors that have the least impact include frequent site accidents due to lack of health and safety measure and lateness to work by workers with IW of $2.881 \%$ and $2.760 \%$, respectively. The critical factors identified explain to a greater extent, the undue delay or total abandonment of some road projects in the study area.

\subsection{Variables Selected for the Model Development}

As in all functional models, logical representations of the dependent and independent variables must be available. For this study, the selection of the parameters to be used in the model development is based on the available project data and the significant relationship among the independent and the dependent variables. In addition, since the intention of the model is not only for the identification and explanation of the parameters affecting delay in road projects but also for use in estimating the delay, the quantitative characteristics or measurability of the values of the variables; availability with reasonable accuracy in the early project stages when conceptual delay estimation is required. The data were derived from selected States of the Niger Delta region in Nigeria, for the road projects procured by NDDC between 2007 and 2016. However, their distributions are not even, with most projects concentrated in some states. Due to this unevenness in distribution, and the very limited representations of the data for most states and year, the time and location influences on the road project data were accounted for and adjusted for through the data normalisation process in the course of developing the model.

The independent variables considered appropriate for this study are; length of the road (LR), initial project Duration (IPD), and the associated critical factors. These road construction process parameters selected are quantitative measures that are well established with precise definition. These parameters are also usually the first few parameters identified for road construction projects with a significant effect on time performance. The delay (time overrun) of the project is the dependent variable for the model, which is designated $\mathrm{P}(\mathrm{Y})$.

\subsection{Ordinal Logistic Regression}

Ordinal logistic regression models determine the probability of an observation fall into a specific group when there are two or more ordered levels of the dependent variable. A specific mathematical tool for developing a model that relates the final duration to the initial duration (delay), magnitude of the road projects (road length), and the causal factors of delay is required. Hence, logistic regression techniques and terminologies associated with them are presented in this section. The logistic regression technique was employed to fit the road project delay in this study. Logistic regression techniques have been used to model probabilistic systems to predict future events (Harrell, 2011) if $p$ is the probability that a binary response variable $Y=1$ when the input variable $X=x$, then the logistic response function is modelled as presented in Equation 6.

$$
p=P(Y=1 \mid X=x)=\frac{e^{\beta_{1}+\beta_{0} x}}{1+e^{\beta_{1}+\beta_{0} x}}
$$

This function represents an s-shaped curve and is non-linear. Here, $\beta$ is the coefficient of the predictor or input variable $x$ used in a regression equation. In Ordinal Logistic Regression (OLR), the response variable can contain more than two ordered levels. The interest may be to decide the likelihood that the response will be one of these levels. When there are three or more ordered categories of the response variable, the ordinal logistic regression (OLR) method is used for modelling (Chatterjee \& Hadi, 2006). The dichotomous dependent variable in binary logistic regression has two levels, 0 and 1, but the ordinal response variable has three or more distinct levels increasing in magnitude. An ordered logit model has the form of Equation 7, 8, and 9.

$$
\begin{gathered}
\log \left(\frac{p_{1}}{1+p_{1}}\right)=\alpha_{k}+\beta^{\prime} X \\
\log \left(\frac{p_{1}+p_{2}}{1-p_{1}-p_{2}}\right)=\alpha_{k}+\beta^{\prime} X
\end{gathered}
$$




$$
\log \left(\frac{p_{1}+p_{2}+\cdots+p_{k}}{1-p_{1}-p_{2}-\cdots-p_{k}}\right)=\alpha_{k}+\beta^{\prime} X
$$

OLR is a logistic regression technique that fits two or more regression curves simultaneously. The equation series above, for example, indicates the odds of belonging to the group represented by $\mathrm{Y}=1$ against belonging to the groups represented by $\mathrm{Y}=2$ to $k$. The numbers of equations modelled in this series are the number of ordered categories minus one. If ( $\mathrm{Y}$ has three ordered levels, then the number of equations modelled are 2). Each of such equations represents its own logit model, and hence the individual equations are called logits. The sum of the probabilities from $P_{1}$ to $P_{k}$ is 1 ; hence, the OLR model's cumulative probability. One crucial assumption in modelling with OLR is that the relationship between independent variables and logits is the same for all the equations in the series (Norusis, 2008). The assumption implies that the coefficients of the independent variables will not vary significantly. Hence, the variable coefficients $\beta$ in all the equations in the series are the same. However, each equation has a different constant term $\alpha_{\mathrm{k}}$.

According to Wiryanto (2018), in OLR analysis, the researchers may have reason(s) to believe that the "distances" between the points of the dependent variable are not equal. For example, the "distance" between "unlikely" and "somewhat likely" may be shorter than the distance between "somewhat likely" and "very likely." It is worthy of note that the intervals for scaling the ordered level of the delay as the dependent variable are not equal. Therefore, this study, in consonance with the suggestion of Wiryanto (2018); scaled the interval for rating delay as; very little, little, moderate, long, and very long, representing $0-5 \%, 6-20 \% ; 21-40 \% ; 41-75 \%$ and $>75 \%$ delay respectively. This was based on several studies revealing that delay, especially in developing countries, is almost like a recurring decimal of every construction project (Aibinu \& Odeyinka, 2006).

For ordinal regression, the regression coefficients are assumed to be the same for all logits. The test for parallelism checks this assumption. The null hypothesis here is that the coefficients of the variables are the same across all response categories. A high significance value $(\mathrm{p}>0.05)$ indicates that the null hypothesis cannot be rejected. These tests have been used in SPSS logistic regression procedures for checking model goodness of fit and validating model assumptions; therefore, it is adopted by this study. Wald's statistic checks how well each predictor contributes to the model individually. Hence, a statistically significant Wald's statistic for a variable indicates that it should be retained in the model. The analysis was conducted with Wald's statistic significant p-value fixed at 0.25. This was based on some previous studies (Mickey \& Greenland, Kavade, 1989; Bendel \& Afifi, 1977), which suggest the adjustment of Wald's statistic significant p-value to 0.25 to enhance the model by capturing almost all the significant variables.

\subsection{Model Fit Indices}

The final model is compared against the baseline to see whether it has significantly improved the fit to the data. The statistically significant chi-square statistic $(\mathrm{p} \leq 0.05)$ indicates that the Final model gives a significant improvement over the baseline intercept-only model. This implies that the model gives better predictions than just guessing based on the marginal probabilities for the outcome categories. Chi-square $\left(\chi^{2}\right)$ tests the null hypothesis that the coefficients of the variables in the model are zero. Hence, if $\chi 2$ is statistically significant $(p<0.05)$, the null hypothesis is rejected. Rejecting the null hypothesis means that the variables enable the model to make better predictions than the model without variables. Pearson's statistic $\left(\mathrm{X}^{2}\right)$ is used along with deviance as an indication of goodness-of-fit. Both values should be small, and the significance values large. The large significance value ( $\mathrm{p}>$ 0.05) indicates that the null hypothesis is rejected, and the model is a good fit (Norusis, 2008).

There are three pseudo-R-squared values generated by OLR analysis (Cox and Snell $\mathrm{R}^{2}$, Nagelkerke $\mathrm{R}^{2}$, and McFadden $\mathrm{R}^{2}$ ). Logistic regression does not have an equivalent to the R-squared that is found in Ordinal Least Square (OLS) regression. Statistical Regression Method in Education (2016) advised that in ordinal logistic regression, the measures of association such as the pseudo $\mathrm{R}^{2}$ are a better method of indexing the goodness of fit than relying on the chi-square significance value, especially when the sample size is large. Hence, this study used the Nagelkerke's Pseudo R-Square value to explain the proportion of variance in the outcome that can be accounted for by the explanatory variables.

\subsection{The Model}

The initial model included the entire contributing variables (evaluated in Table 1), the 29 critical impact factors, and the two ratios scaled variables (road length and initial project duration). At first, the model was compared against the baseline to observe whether it has significantly improved the fit to the data. The statistically significant chi-square statistic ( $\mathrm{p}=0.043<0.05$ in Table 3 ) indicates that the initial model gives a significant improvement over the baseline intercept-only model. This implies that the model predicts better than just guessing based on the marginal probabilities for the outcome categories. 
The first leg of OLR was run in order to reduce the 31 variables to the number that is most significant and suitable for the model. It is worthwhile explaining the information extracted, as presented in Table 3. The Model Fitting Information gives hints about determining whether the model improves the ability to predict the outcome. This is done by comparing a model without any explanatory variables (the baseline or 'Intercept Only' model) against the model with all the explanatory variables (the 'Final' model) on the basis of the significant value of the chi-square $(\mathrm{p} \leq 0.05$ for this study). Although, the model did pass the test of parallel lines $(\mathrm{p}=0.246>0.05)$, which determines if the coefficients of the variables are the same for all logits in the ordinal logistic regression model as presented in Table 4, some of the variables' Wald's statistic significant values were above the targeted value of 0.25 . Therefore, the variables which did not contribute significantly towards the prediction of the model were eliminated from further analysis.

Table 3: Delay Model Fitting Information

\begin{tabular}{lrrrr}
\hline Model & $\mathbf{- 2}$ Log Likelihood & Chi-Square & Df & Sig. \\
\hline Intercept Only & 334.545 & & & \\
Final & 283.974 & 50.571 & 35 & 0.043 \\
\hline
\end{tabular}

Link function: Logit.

Table 4: Initial Delay Model Test of Parallel Lines

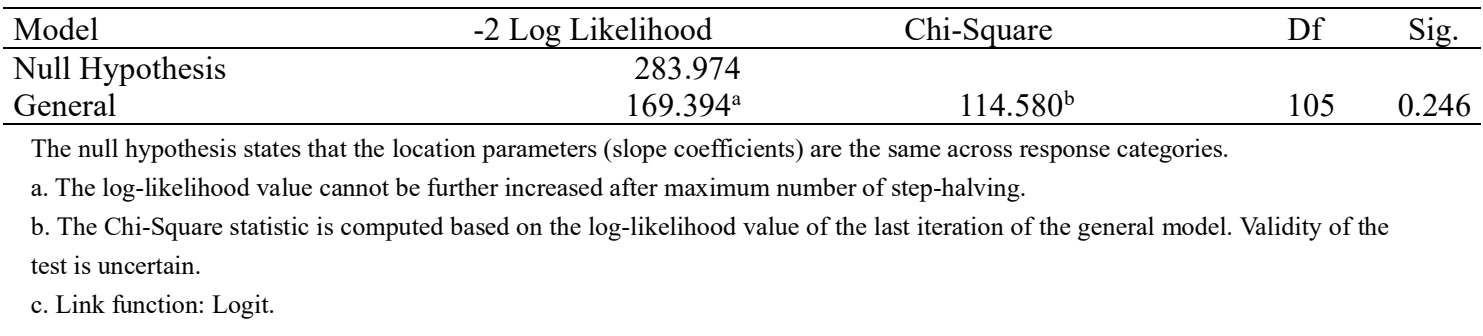

The remaining variables were selected for fitting in further models. The variables that had their Wald's statistic significant at a $p$-value $\leq 0.25$ were selected for fitting in the next model. The procedure continued until all constants and variables had a significant Wald's statistic. The final model for predicting delay in a road construction project has eleven independent variables that are significant, as shown in Table 5. The delay model was developed based on the eleven significant variables with the model fitting information of 324.030 of 2Log likelihood, chisquare of 41.19 , and the significance level of 0.000 , indicating the fitness and suitability of the variables to the model as presented in Table 6 .

Table 5: Final Model for Delay Parameter Estimates

\begin{tabular}{llrrrrrrr}
\hline & \multirow{2}{*}{ Variable ID } & \multicolumn{3}{c}{ Std. } & & \multicolumn{3}{c}{ 95\% Confidence Interval } \\
& Estimate & \multicolumn{1}{c}{ Error } & Wald & Df & Sig. & Lower Bound & Upper Bound \\
\hline Threshold & {$[\mathrm{DL}=1,00]$} & -6.024 & 1.881 & 10.252 & 1 & .001 & -9.712 & -2.337 \\
(Dependent & {$[\mathrm{DL}=2,00]$} & -4.484 & 1.848 & 5.888 & 1 & .015 & -8.105 & -.862 \\
Variable) & {$[\mathrm{DL}=3,00]$} & -2.854 & 1.820 & 2.460 & 1 & .117 & -6.420 & .712 \\
& {$[\mathrm{DL}=4,00]$} & -.502 & 1.802 & .077 & 1 & .781 & -4.034 & 3.030 \\
Independent & F5 & .408 & .230 & 3.144 & 1 & .076 & -.043 & .860 \\
Variable & F18 & -.361 & .226 & 2.554 & 1 & .110 & -.803 & .082 \\
& F37 & .699 & .280 & 6.234 & 1 & .013 & .150 & 1.248 \\
& F38 & .555 & .278 & 3.985 & 1 & .046 & .010 & 1.100 \\
& F47 & .843 & .281 & 9.015 & 1 & .003 & .293 & 1.393 \\
& F54 & -.507 & .258 & 3.868 & 1 & .049 & -1.013 & -.002 \\
& F61 & -.370 & .211 & 3.069 & 1 & .080 & -.785 & .044 \\
& F66 & -.929 & .265 & 12.249 & 1 & .000 & -1.449 & -.409 \\
& F73 & -.388 & .196 & 3.933 & 1 & .047 & -.771 & -.005 \\
& F117 & -.425 & .267 & 2.526 & 1 & .112 & -.949 & .099 \\
& RL & -.388 & .175 & 4.895 & 1 & .027 & -.732 & -.044 \\
\hline
\end{tabular}

Link function: Logit.

a. This parameter is set to zero because it is redundant. 
Table 6: Final Model Fitting Information for Delay

\begin{tabular}{lcccc}
\hline Model & $\mathbf{- 2 ~ L o g ~ L i k e l i h o o d ~}$ & Chi-Square & Df & Sig. \\
\hline Intercept Only & 324.030 & & & \\
Final & 282.842 & 41.187 & 15 & 0.000 \\
\hline
\end{tabular}

Link function: Logit.

The variables were slow decision making (F5), incompetent technical staff (F18), improper contract packaging/delivery (F37), poor coordination of contract information (F38), irregular attendance at meetings (F47), lack of skilled and unskilled site manpower (54), lack of training of workers (F61), frequent site accidents due to lack of health and safety measures(F66), interference by political leaders (government interest) (F73), poor handling of materials (F117) and road length (RL). These are variables that predict the delay of road projects procured by NDDC in the study area. Therefore, quick and fast decision making by firms and organisations involved in the execution of road projects is an essential requirement to solve uncertain happenings and to improve the productivity and quality of construction projects because slow decision making hinders performance. Competent technical staff must be employed by the organisations as well for technical work to be executed appropriately. In the case of the feasibility study, experienced staff must be assigned to carry out such tasks for proper documentation based on contract requirements and specifications to minimise the frequent occurrence of errors during execution. Employing competent staff and expertise for adequate monitoring and supervision of the projects is imperative. Above all, cost control measures should be ensured in the aspect of materials waste and supply of inferior materials to the site, which may result in time and money wastage. The consultant's decisions and implementation of the resolutions must be adequate to avoid conflict resulting from delaying.

Attendance at site meetings for essential and useful information becomes necessary for timely completion of road projects. Training for the workers helps to boost productivity on-site as workers are exposed to new ideas and management techniques. Skilled and unskilled manpower must be available on-site for a productive workforce. Interference by political leaders had manifested in them seeking their interest through misappropriation of funds meant for projects. This had resulted in delayed release of funds to contractors and automatically affected the programme of work, thus leading to delay or outrightly abandonment.

The length of the road project must be taken into consideration as no two projects are the same, and the cost and duration of road projects should be a function of the length coverage, all other factors being equal. The length of the road 'A may be the same as the length of road 'B' but the location, in terms of topography, climatic condition, and even soil texture may not be the same. Therefore, the construction methodology and managerial approach will differ. However, if the contractor and consultant regard road projects as just a linear project, without giving adequate attention to the preliminary stage of the work, and unwarranted delay may occur. Adequate feasibility study of the project is also vital for a proper understanding of the in-depth task involved before award and commencement of work to avoid delay and abandonment. By so doing, it will help to determine the realistic duration of the project as an unrealistic contract duration-imposed review during site operation, thereby elongating the time frame.

Appendix 1 shows the resulting models based on the delay variables. These were developed based on the critical impact factors as represented in equations 10,11, 12, and 13. Appendix 2 captured the mathematical interpretation of the model using the probability formulae. Equation 14 in Appendix 2 represents the fifth-order, which is simply unity (1) minus the Probability of the fourth one.

\subsection{Model Validation}

There are many techniques for assessing a good internal validation of the model's performance. This study opted for data-splitting, which is a form of cross-validation using $3 / 4$ development (training). The $1 / 4$ validation is sometimes referred to as the split-quarter cross-validation method. This $3 / 4$ method is preferred because it matters less about how the data gets divided, and selection bias will not be present. Additionally, it prevents data replacement during validation, unlike bootstrapping. Consequently, a duplication of the subjects in the original sample is avoided. Although bootstrapping appears to be a compelling technique, this study chose not to use it in order to obtain easily interpretable results and due to high computation time required. Data-splitting is preferred to the jack-knife technique because the former provides more data for model testing purposes.

To avoid biases in selecting the validation sample, all the questionnaires collected were sorted, and the valid 117 copies were numbered serially. MS Excel was used to generate the randomly selected copies used for validating the developed model. RANDBETWEEN (1:117) in the formula bar generated thirty-one random numbers, which 
guided the selection and separation of the questionnaires meant for model validation from the 117 valid copies with the balance of eighty-six. The data for model validation were generated from the thirty-one questionnaires set aside for validating the model, which represents about one-quarter of the sample size.

The validation process was carried out in order to compare the original data collected from the surveys for modelling the data separated for validation. This process began by comparing the marginal probabilities for each category response in the data obtained from the survey and the validation data. Two approaches were used for validating the model. The first approach was the execution of the mean rank test followed by a case study approach through substitution of the validated data into the developed model to observe its degree of reliability. The study used data collected from three (3) clients' representative firms, eight (8) consulting, and twenty (20) contracting organisations to validate the developed model with eleven independent input variables and one output dependent variable. The study performed a mean rank test to determine whether the mean rank between the model data and the validated data was statistically different or not. The mean ranks for the model data, and the validated data are shown in Table 7.

Table 7: Mean Rank of Time Performance Determinants

\begin{tabular}{|c|c|c|c|c|}
\hline Significant variables & Variable ID & Data type & Mean Rank & Sum of Ranks \\
\hline \multirow[t]{2}{*}{ Slow decision making } & F5 & Model & 76.28 & 8925.00 \\
\hline & & Validation & 67.77 & 2101.00 \\
\hline \multirow[t]{2}{*}{ Incompetent technical staff } & F18 & Model & 76.96 & 9004.50 \\
\hline & & Validation & 65.21 & 2021.50 \\
\hline \multirow[t]{2}{*}{ Improper contract packaging/delivery } & F37 & Model & 75.86 & 8876.00 \\
\hline & & Validation & 69.35 & 2150.00 \\
\hline \multirow{2}{*}{$\begin{array}{l}\text { Poor coordination of contract } \\
\text { information }\end{array}$} & F38 & Model & 76.74 & 8978.00 \\
\hline & & Validation & 66.06 & 2048.00 \\
\hline \multirow[t]{2}{*}{ Irregular attendant at site meeting } & F47 & Model & 73.61 & 8612.00 \\
\hline & & Validation & 77.87 & 2414.00 \\
\hline \multirow{2}{*}{$\begin{array}{l}\text { Lack of skilled and unskilled site } \\
\text { manpower }\end{array}$} & F54 & Model & 75.10 & 8786.50 \\
\hline & & Validation & 72.24 & 2239.50 \\
\hline \multirow[t]{2}{*}{ Lack of training of workers } & F61 & Model & 77.64 & 9083.50 \\
\hline & & Validation & 62.66 & 1942.50 \\
\hline \multirow{2}{*}{$\begin{array}{l}\text { Frequent site accident due to lack of } \\
\text { health and safety measures }\end{array}$} & F66 & Model & 74.81 & 8752.50 \\
\hline & & Validation & 73.34 & 2273.50 \\
\hline \multirow{2}{*}{$\begin{array}{l}\text { Interference by political leader } \\
\text { (Government interest) }\end{array}$} & F73 & Model & 75.62 & 8847.50 \\
\hline & & Validation & 70.27 & 2178.50 \\
\hline \multirow[t]{2}{*}{ Poor handily of materials } & F117 & Model & 75.14 & 8791.50 \\
\hline & & Validation & 72.08 & 2234.50 \\
\hline \multirow[t]{2}{*}{ Road Length (Binned) } & RL & Model & 74.32 & 8695.00 \\
\hline & & Validation & 75.19 & 2331.00 \\
\hline
\end{tabular}

The mean ranks of the model data were slightly higher than the ones of the validated data for all of the eleven variables. The asymptotic significance values for each of the determinant factors of delay are reflected in Table 8 using the Mann-Whitney $U$ test, based on the significant value of $\alpha=0.05$. All the asymptotic significance values were greater than the specified $\alpha$. Thus, there is no significant difference between the mean ranks on all of the tested variables from the data used for developing the model and the validating data. These results confirm that the model developed is valid and can be used for prediction purposes.

Table 8: Mean Rank Test Statistics

\begin{tabular}{|c|c|c|c|c|c|c|c|c|c|c|c|}
\hline Variable ID & F5 & F18 & F37 & F38 & F47 & F54 & F61 & F66 & F73 & F117 & RL \\
\hline Mann-Whitney U & 1605.00 & 1525.50 & 1654.00 & 1552.00 & 1709.00 & 1743.50 & 1446.50 & 1777.50 & 1682.50 & 1738.50 & 1792.00 \\
\hline Wilcoxon W & 2101.00 & 2021.50 & 2150.00 & 2048.00 & 8612.00 & 2239.50 & 1942.50 & 2273.50 & 2178.50 & 2234.50 & 8695.00 \\
\hline $\mathrm{Z}$ & -1.043 & -1.424 & -.796 & -1.286 & -.533 & -.346 & -1.819 & -.177 & -.664 & -.367 & -.128 \\
\hline $\begin{array}{l}\text { Asymp. } \\
\text { Sig. (2-tailed) }\end{array}$ & 297 & .154 & .426 & 198 & .594 & .729 & .069 & .859 & .507 & .714 & .898 \\
\hline
\end{tabular}

In summary, the inference is drawn that there was no significant difference between the mean ranks of all of the 
tested variables from the data used for developing the model and the validating data. Thus, the eleven critical impact factors assessed in the model were very significant to the delay in the construction of road projects procured by NDDC in the study area. The model, therefore, offers a tool to predict likely delay occurrence in road projects, which could assist with installing adequate planning techniques at the project inception.

\subsection{Case Studies for Model Validation}

The five (5) cases used for this validation were part of the thirty-one (31) not used earlier for constructing the model. Each case had been rated for a delay (the dependent variable) and other independent variables. The Probability that a case with given input variables has a particular delay rating was determined using the formulae in Appendix 2. Each case where the variables from the group of independent variables included in the model were identified as significant and could provide the inputs between scale 1-5 for the equations were selected. The substituted values of each variable selected for case study validation are presented in Table 9, while the computational procedure is shown in tabular form in Appendix 4.

Table 9: Values of Significant Variables in the Cases Employed for Model Validation

\begin{tabular}{ccccccccccccc}
\hline CASE & F5 & F18 & F37 & F38 & F47 & F54 & F61 & F66 & F73 & F117 & RL & Observed Delay \\
\hline $\mathbf{1}$ & 3 & 3 & 3 & 3 & 3 & 3 & 2 & 2 & 4 & 2 & 1 & 5 \\
$\mathbf{2}$ & 2 & 2 & 3 & 2 & 2 & 2 & 4 & 2 & 5 & 2 & 1 & 3 \\
$\mathbf{3}$ & 3 & 3 & 3 & 3 & 2 & 3 & 3 & 2 & 3 & 2 & 1 & 3 \\
$\mathbf{4}$ & 3 & 2 & 3 & 2 & 2 & 2 & 2 & 1 & 4 & 1 & 1 & 5 \\
$\mathbf{5}$ & 4 & 3 & 3 & 1 & 3 & 2 & 1 & 1 & 5 & 2 & 1 & 5 \\
\hline
\end{tabular}

Cases were categorised as being correctly predicted if the calculated Probability was above 0.50 based on SPSS default. For example, (refer to Table 10) for case 1 in particular, delay rating observed belonged to a very long level (Delay of 5$)$. The Probability calculated $(0.506>0.50)$ classified this case as being correctly predicted. In another case selected (case 4), the delayed rating fitted to a very long level (Delay of 5). The high calculated probability value $(0.70>0.50)$ classified this case as being correctly predicted. This explanation holds for cases 3 and 5 . Likewise, in case 2, the delayed rating belonging to a moderate level (Delay of 3 ) was selected. The calculated probability value $(0.297<0.50)$ classified this case as not correctly predicted. Careful examination of the trend of the calculated probabilities in case 2 shows a gradual increase up to 0.462 , then a sudden drastic decline to 0.115 . Graphically, the curve of the probabilities is parabolic, with an optimum value between delays of 3 and 4 . This indicates that the case is equally correctly predicted. Having established the validity of the model, it was concluded that the model could be used to predict the level of delay anticipated in road construction projects within the study area.

Table 10: Case Studies of Model Validation Examples

\begin{tabular}{cccccccc}
\hline \multirow{2}{*}{ Case } & \multirow{2}{*}{ Observed Delay } & \multicolumn{4}{c}{ Predicted Probability that Delay will be: } & \multicolumn{2}{c}{$\begin{array}{c}\text { Correctly } \\
\text { Predicted? }\end{array}$} \\
\cline { 3 - 6 } & & Eq. 1 & Eq. 2 & Eq. 3 & Eq. 4 & Eq. 5 & Predics \\
1 & 5 & 0.004 & 0.014 & 0.067 & 0.409 & 0.506 & Yes \\
2 & 3 & 0.030 & 0.096 & 0.297 & 0.462 & 0.115 & Yes \\
3 & 3 & 0.009 & 0.031 & 0.515 & 0.135 & 0.31 & Yes \\
4 & 5 & 0.000 & 0.008 & 0.031 & 0.261 & 0.700 & Yes \\
5 & 5 & 0.002 & 0.007 & 0.034 & 0.279 & 0.678 & Yes \\
\hline
\end{tabular}

\section{Conclusions and Recommendations}

This study examined delay in road project delivery in a special scenario where time performance is influenced by factors other than funding described as 'no funding stress' scenario. A case study using NDDC road projects was used to model the delay causative variables in this scenario to provide the understanding of predicting project delay quantum from the inception of road construction. Inferential statistics, rating weighted agreement (RWA), and impact weighting (IW) were employed to isolate the critical delay factors. Ordinal logistic regression (OLR) was used to model the delay factors, and final models were validated using the split-quarter cross-validation method.

The critical factors obtained from the RWA and subsequently evaluated through IW revealed 29 variables that were significant to untimely completion of road construction projects in the study area. These 29 critical factors 
represent about $22.14 \%$ of the one-hundred, and thirty-one (131) variables examined and could be adequately defined as critical delay causative factors in typical 'no funding stress' scenario of road projects. Two stages of regression analysis were undertaken in order to model the 29 variables as the basis of predicting project delay quantum in the scenario. The first part of the OLR was run in order to reduce the 29 variables to numbers that most suitably fit the model. Therefore, the variables which did not contribute significantly towards the prediction of the model were eliminated from further analysis.

The final model has eleven variables that significantly contribute to it. The variables which had their Wald's statistic significant at a $p$-value $<0.25$ were selected for fitting the model. The delay model was developed based on the 11 significant variables with the model fitting information of 324.030 of 2 Log likelihood, chi-square of 41.19, and the significance level of 0.000 , indicating the fitness and suitability of the variables to the model. The model was validated using a data-splitting method, which is a form of cross-validation using 3/4 development (training) and $1 / 4$ validation, sometimes referred to as the split-quarter cross-validation method. All cases selected for case study validation were categorised as being correctly predicted, which established the validity of the model. Therefore, it was concluded that the model could be used to predict the level of delay anticipated in road construction project delivery in the 'no funding stress' scenario.

It is recommended that stakeholders in construction should pay adequate attention to the identified critical impact factors to improve upon the time performance and delivery of road construction projects. The study provided useful insights into road project management in the case of a special intervention scheme. Empirical evidence provided is suitable for managing road project delivery in a 'no funding stress' scenario through the development of the prediction tool for improvement on time performance. In addition, the study modelled the time variables in this scenario to assist in predicting likely delay quantum and guide the selection of appropriate project planning tool from inception. The findings are also expected to provide implications for government policy response, which would guide the delivery of regional intervention projects. Research efforts at developing similar models that combine the 'cost-time' matrix in road projects would put the scope of the study in a broader perspective.

\section{References}

Abdullah, A. (2013). "Factors Affecting Cost Overruns in Road Construction Projects in Saudi Arabia," International Journal of Civil and Environmental Engineering, Hail University Hail KSA.13(3),1-4.

Adewuyi, T. O., Idoro, G. I.\& Ikpo, I. J. (2014)." Empirical Evaluation of Construction Material Waste Generated on Sites in Nigeria", Civil Engineering Dimension, 16 (2), 96-103.

Aibinu, A. \& Odeyinka, H. (2006). "Construction Delays and their Causative Factors in Nigeria," Journal of Construction and Engineering Management, 132 (7), 667-677.

Al-Kharashi, A. \& Skitmore, M. (2009). "Causes of Delays in Saudi Arabia Public Sector Construction Projects," Construction Management and Economics, 27 (1), 3-23.

Al-Momani, A. H. (2000). "Construction Delay: A Quantitative Analysis," International Journal of Project Management, 18 (1), 51-59.

Alphonsus, O. \& Mohammad, B. (2015). Socio-Economic Impact of Niger Delta Development Commission (NDDC) Infrastructure Projects in Selected Communities in Imo State Nigeria", Asian Journal of Human and Social Science (AJHSS), 3 (2), 109-112.

Anoruo, E. \& Braha, H. (2012). Corruption and Economic Growth: The African Experience", Journal of Sustainable Development in Africa, 7 (1), 43-55.

Bangash, Z. K. (2016). "Analyzing the Causes of Delays in Construction Projects for Peshawar: Contractor Perception," Journal of Emerging Trends in Applied Engineering, 1(1), 13-18.

Basheka, C. B.\& Tumutegyereize, M. (2012). "Measuring the Performance of Contractors in Government Construction Projects in Developing Countries: Uganda's Context," African Journal of Business Management, 6 (32), 9210-9217. https://doi.org/10.5897/AJBM11.923

Bendel, R. \& Afifi, A. (1977). "Comparison of Stopping Rules in Forwarding Regression," Journal of the American Statistical Association, 72, 46-53.

Chatterjee, H., \& Hadi, A. (2006). "Regression Analysis by Example," Hoboken, N.J: Wiley.

Dafinone, D. O. (2007). The Niger Delta Crisis: Genesis the Exodus and the Solution", Chairman's Address at the Niger Delta Peace Conference, Abuja, Nigeria. 
Divya, R. \& Ramya, S. (2015). "Causes, Effects and Minimization of Delays in Construction Projects," Proceedings of National Conference on Research Advance in Communication, Computation, Electrical Science and Structures (NCRACCESS), 2015, 47-53.

Ekanem, S. F. (2019). "Impact of Delay on the Performance of Road Projects Procured by Niger Delta Development Commission, Nigeria", PhD Thesis in the Department of Quantity Surveying, Faculty of Environmental Design and Management, Obafemi Awolowo University, Ile-Ife, Nigeria.

Elinwa, U. \& Buba, S. (1994). "Construction Cost Factors in Nigeria," Journal of Construction Engineering and Management, 119(4), 698 - 714.

Enshassi, A., Mohamed, S. \& Abushaban, S. (2009). "Factors Affecting the Performance of Construction Projects in the Gaza strip," Journal of Civil Engineering and Management, 15 (3), 269-280. https://doi.org/103846/1392-3730.2009.15269-280

Harrell, F. E. (2011). "Regression Modelling Strategies-with Application to Linear Models, Logistic Regression and Survival Analysis," New York: Springer-Verlag Inc., 215-221.

Haseeb, M., Xinhai-Lu, A., Bibi, A., Maloofud, D.\& Rabbani, W. (2011). "Problems of Projects and Effects of Delays in the Construction Industry of Pakistan," Australian Journal of Business and Management Research 1(5), 41-50.

Hair, J.F.J., Anderson, R.E., Tatham, R.L. \& Black, W.C. (2006). "Multivariate Data Analysis, 6th Edition., Pearson Prentice-Hall, Upper Saddle River, N.J.

Isidiho, A. O. \& Sabran, M. S. B. (2015). "Challenges Facing Niger Delta Development Commission (NDDC) Projects in Imo State and Niger Delta Region in Nigeria," International Journal of Humanities and Social Science, 5 (6), 37-48.

Isidiho, A. O. \& Sabran, M. S. B. (2015). "Socio-Economic Impact of Niger Delta Development Commission (NDDC) Infrastructure Projects in Selected Communities in Imo State Nigeria," Asian Journal of Human and Social Science (AJHSS) 3 (2), 109-113.

Kariungi, S. M. (2014). "Determinant of Timely Completion of Projects in Kenya: A Case of Kenya Power and Lighting Company, Thika," ABC Journal of Advanced Research. 3(2), 9-19. https://doi.org/10.18039/ABC.JARV312.33

Kavade, H., A. (2009). "Logistic Regression Model to Predict Incident Severity using the Human Factors Analysis and Classification System," M. Sc. Thesis in Industrial Engineering. The Graduate School of Clemson University.

Kikwasi, G. J. (2012). "Causes and Effects of Delays and Disruptions in Construction Projects in Tanzania," Australasian Journal of Construction Economics and Building Conference Series, 1(2), 52-59.

Kothari C. R. (2004). "Research methodology methods and techniques," Second Revised Edition, New Age International (P) Limited Publishers, New Delhi.

Kulemeka, P. J., Kululanga, G.\& Morton, D. P. (2015). "Critical Factors Inhibiting Performance of Small and Medium Scale Contractors in Sub- Saharan Region: A case for Malawi," Journal of Construction Engineering (2015), 1-17 https://doi.org/10.1155/2015/927614

LeBreton, J. \& Senter, J. (2008). "Answers to 20 Questions About Inter-rater Reliability and Inter-rater Agreement", Organizational Research Methods, 11(4), 815-852.

Leedy, P. D. \& Ormrod. J. E. (2010). "Practical Research: Planning and Designing," Ninth Edition, Upper Saddle River, New Jersey: Pearson

Lyulina, A., Onishi, M. \& Kobayashi, K. (2015). "Delay Analysis Methods for Construction Project: Mathematical Modelling," Project Advisors International 3(1), 27-36.

Manavazhia, M. \& Adhikarib, D. (2002). "Material and Equipment Procurement Delays in Highway Projects in Nepal," International Journal of Project Management, 20, 627-632. P11:50263-7863(02)00027-3

Mwawasi, S. W. (2015). "Time and Cost Overruns in Road Construction Projects in Kenya Under Kenya National Highways Authority," Master's Thesis, University of Nairobi, Kenya.

Mulla, S. S. \& Waghmare, A. P. (2015). "A Study of Factors Caused for Time and Cost Overruns in Construction Project and their Remedial Measures," Journal of Engineering Research and Applications, 5(1), 48-53.

Norusis, M. (2008). "SPSS 16.0 Advanced Statistical Procedures Companion", Upper Saddle River, N.J: Prentice 
Hall.

Odesola, I. A. (2012). "Construction Labour Productivity of Masonry Operations in South-South, Nigeria", PhD Thesis, Department of Building, Faculty of Environmental Studies, University of Uyo, Nigeria.

Opawole, A. (2015). "Assessment of Parties Obligation in Concession-Based Projects in Southwestern, Nigeria", $\mathrm{PhD}$ Thesis in the Department of Quantity Surveying, Faculty of Environmental Design and Management, Obafemi Awolowo University, Ile-Ife, Nigeria.

Opawole A. \& Jagboro G.O (2016). "Factors influencing the scope of private party's obligations in concessionbased PPP projects in Nigeria," Structural Survey, 34 (3), 297 -314.

Shahid, A., Ahmad, H., Ahmad, N., Shafique, M. N. \& Amjad, N. (2015). "Analysis of key Performance Factors Affecting Residential Construction Projects in Pakistan," Arabian Journal of Business and Management Review 3(10), 9-14. https://doi.org/10.12816/0017682

Silva, A. \& Nobre, N. (2018). "Students' Entrepreneurial Propensity: An Exploratory Study from a Portuguese Polytechnic School," Journal of Entrepreneurship and Organization Management, 7(1), 1-6.

Simon, J. (2017). "The Factors Causing Delays in Road Construction Projects in Tanzania: A Case of Tanroad Dar Es Salaam City," M.Sc. in Project Management Dissertation, The Open University of Tanzania.

Statistical Regression Method in Education, SRME (2016). "ReStore - National Centre for Research Method," Using Statistical Regression Methods in Education Research (Module5), Retrieved from http://www.restore.ac.uk/srme/www/fac/soc/wie/research-new/srme/index.html on August 6, 2016.

Sunjka, B. P. \& Jacob, U. (2013). Significant Causes and Effects of Project Delays in the Niger Delta Region, Nigeria. Stellenbosch, South Africa, SAIIE25 Proceedings, $9^{\text {th }}-11^{\text {th }}$ of July, Stellenbosch, South Africa, 641$1-641-14$

Umoren, O. (2014). "Site Analysis and Report, A Basic Requirement in Planning for Construction," A Paper Delivered on $9^{\text {th }-} 11^{\text {th }}$ October, The Nigerian Institute Quantity Surveyors National Training Workshop, Uyo, Akwa Ibom State, Nigeria, 2014.

Wiryanto, H. (2018). "Ordinal Logistic Regression,"2017,https://rstudio-pubs-static.s3. amazonaws.com/312159_b70bcec4005947c3892d092fa9b257f7.html, accessed April 11, 2018.

Appendix 1: Output of Ordinal Logistic Regression of Modelling Delay of Rad Project in Niger Delta, Nigeria

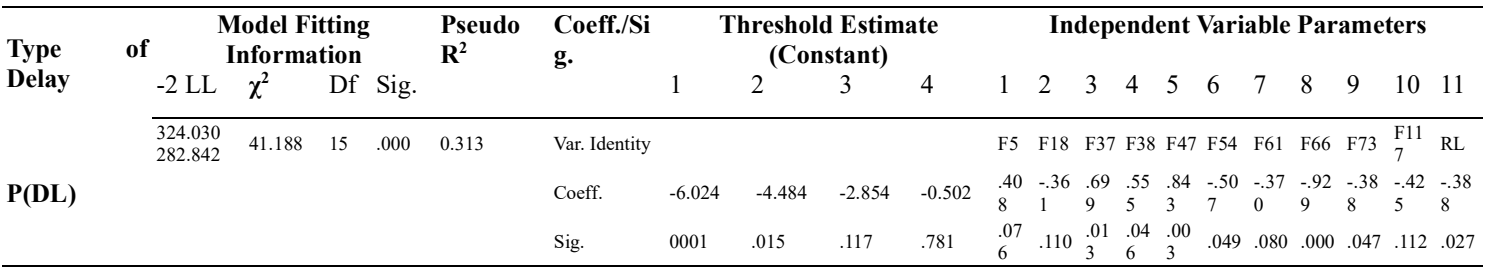




\section{Appendix 2: Probability Formulae (Mathematical Interpretation of the Model}

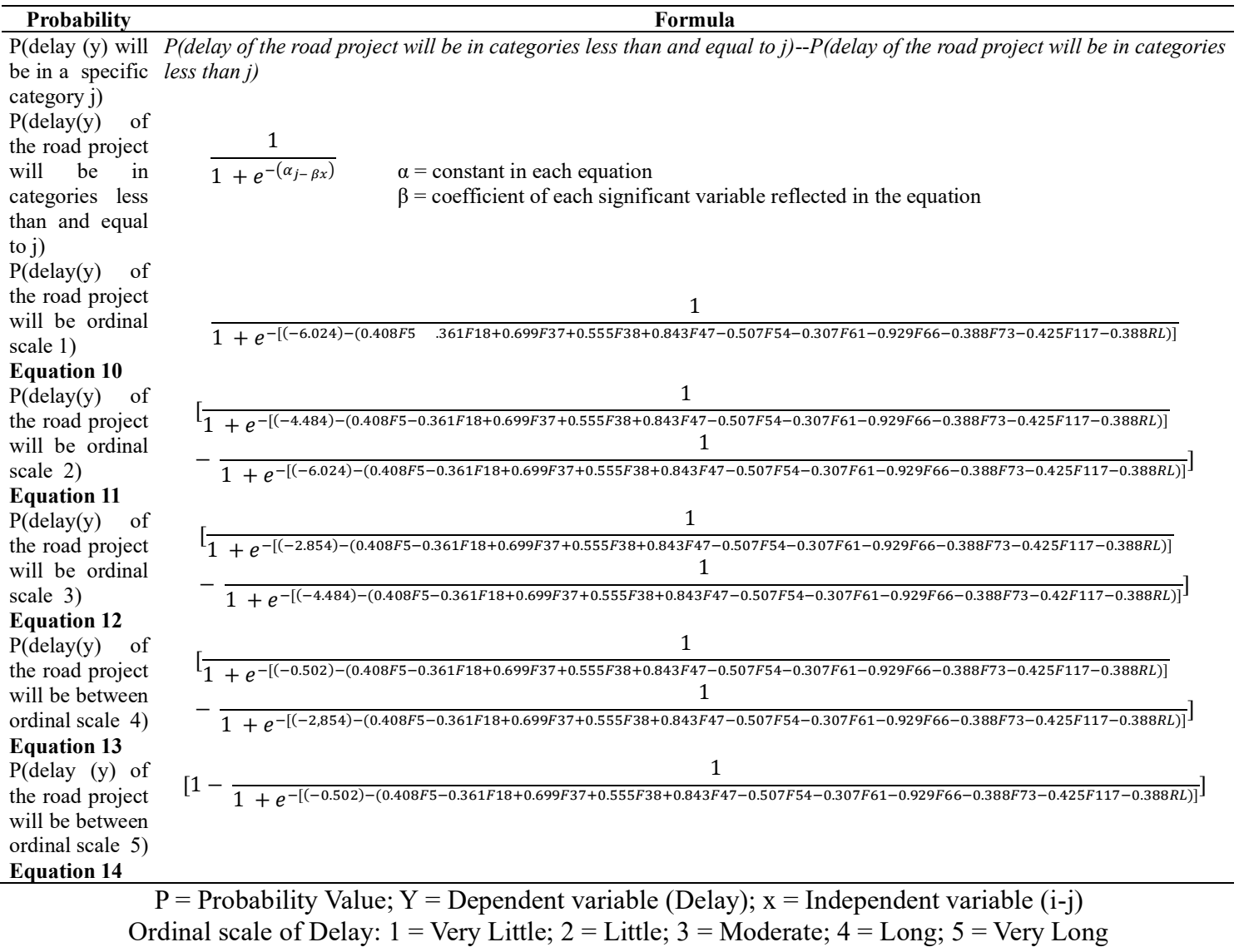

\section{Appendix 3}

Determining the Critical Impact Factor of Delay

\begin{tabular}{|c|c|c|c|c|c|c|}
\hline Factors Impacting Delay of Road Projects & Sum & Mean & $\begin{array}{l}\text { Std. } \\
\text { Deviation }\end{array}$ & Variance & RWG & Decision \\
\hline Late procurement of materials & 381.00 & 3.2564 & .82162 & .675 & 0.66 & MA \\
\hline Irregular attendant at site meeting & 324.00 & 2.7692 & .87479 & .765 & 0.62 & MA \\
\hline Shortage of construction materials on site & 312.00 & 2.6667 & .90019 & .810 & 0.59 & MA \\
\hline $\begin{array}{l}\text { Late identification of errors and omissions in contract } \\
\text { document }\end{array}$ & 340.00 & 2.9060 & .91898 & .845 & 0.58 & MA \\
\hline Non-compliance to contract conditions & 362.00 & 3.0940 & .92832 & .862 & 0.57 & MA \\
\hline Under estimation of materials & 301.00 & 2.5726 & .93141 & .868 & 0.57 & MA \\
\hline Late drawing and specification delivery & 316.00 & 2.7009 & .94015 & .884 & 0.56 & MA \\
\hline Inadequate feasibilities study & 345.00 & 2.9487 & .95454 & .911 & 0.54 & MA \\
\hline Fluctuation in the price of materials & 420.00 & 3.5897 & .95731 & .916 & 0.54 & MA \\
\hline Interference by political leader (Government interest) & 454.00 & 3.8803 & .95739 & .917 & 0.54 & MA \\
\hline Incompetent technical staff & 327.00 & 2.7949 & .96077 & .923 & 0.54 & MA \\
\hline Unavailability of special equipment for special work & 305.00 & 2.6068 & .96452 & .930 & 0.53 & MA \\
\hline Change in government regulation and market condition & 399.00 & 3.4103 & .96627 & .934 & 0.53 & MA \\
\hline Incompetent foreman & 321.00 & 2.7436 & .96627 & .934 & 0.53 & MA \\
\hline Poor materials management on site & 301.00 & 2.5726 & .96772 & .936 & 0.53 & MA \\
\hline Lack of training of workers & 318.00 & 2.7179 & .97243 & .946 & 0.53 & MA \\
\hline Mobilization delay & 478.00 & 4.0855 & .97885 & .958 & 0.52 & MA \\
\hline Lack of skilled and unskilled site manpower & 323.00 & 2.7607 & .97953 & .959 & 0.52 & MA \\
\hline Lateness to work by workers & 273.00 & 2.3333 & .98261 & .966 & 0.52 & MA \\
\hline Change orders from client & 328.00 & 2.8034 & .98470 & .970 & 0.52 & MA \\
\hline Rework due to changes ordered by the client or consultant. & 341.00 & 2.9145 & .98762 & .975 & 0.51 & MA \\
\hline Lack of incentive to motivate the workforce & 324.00 & 2.7692 & .99468 & .989 & 0.51 & MA \\
\hline Low quality/ standard of material supply & 327.00 & 2.7949 & .99601 & .992 & 0.51 & MA \\
\hline
\end{tabular}




\begin{tabular}{|c|c|c|c|c|c|c|}
\hline Factors Impacting Delay of Road Projects & Sum & Mean & $\begin{array}{c}\text { Std. } \\
\text { Deviation }\end{array}$ & Variance & RWG & Decision \\
\hline Poor handling of materials & 308.00 & 2.6325 & .99653 & .993 & 0.51 & MA \\
\hline Delay by sub-contractor's work & 330.00 & 2.8205 & .99668 & .993 & 0.51 & MA \\
\hline High rate of inflation & 447.00 & 3.8205 & .99668 & .993 & 0.51 & MA \\
\hline Slow decision making & 326.0 & 2.786 & .99985 & .995 & 0.51 & MA \\
\hline Poor coordination of contract information & 325.00 & 2.7778 & .99986 & .995 & 0.51 & MA \\
\hline Improper contract packaging/delivery & 331.00 & 2.8291 & .99988 & .997 & 0.51 & MA \\
\hline Frequent site accident due to lack of health and safety measures & 285.00 & 2.4359 & .99998 & .997 & 0.49 & WA \\
\hline Poor quality of material supply & 340.00 & 2.9060 & 1.00844 & 1.017 & 0.49 & WA \\
\hline $\begin{array}{l}\text { Delay in providing services from utilities (electricity, water } \\
\text { etc) }\end{array}$ & 333.00 & 2.8462 & 1.01383 & 1.028 & 0.49 & WA \\
\hline Poor relationship among the stakeholders & 332.00 & 2.8376 & 1.01673 & 1.034 & 0.48 & WA \\
\hline Inertia in government bureaucracies & 399.00 & 3.4103 & 1.01840 & 1.037 & 0.48 & WA \\
\hline Contract document errors, omission and inconsistency & 331.00 & 2.8291 & 1.01956 & 1.039 & 0.48 & WA \\
\hline High rate of corruption & 437.00 & 3.7350 & 1.02042 & 1.041 & 0.48 & WA \\
\hline Absence of workers on site & 299.00 & 2.5556 & 1.02086 & 1.042 & 0.48 & WA \\
\hline Irregular payment to labour & 341.00 & 2.9145 & 1.02194 & 1.044 & 0.48 & WA \\
\hline Change order by the client & 291.00 & 2.4872 & 1.02230 & 1.045 & 0.48 & WA \\
\hline Shortage of labour & 271.00 & 2.3162 & 1.02259 & 1.046 & 0.48 & WA \\
\hline Liquidation damage and dispute & 314.00 & 2.6838 & 1.02259 & 1.046 & 0.48 & WA \\
\hline Strike and dispute by the labour & 307.00 & 2.6239 & 1.02323 & 1.047 & 0.48 & WA \\
\hline Lack of resident consultant. & 324.00 & 2.7692 & 1.02876 & 1.058 & 0.47 & WA \\
\hline Poor communication and coordination among parties & 336.00 & 2.8718 & 1.03005 & 1.061 & 0.47 & WA \\
\hline Prolong awaiting time for inspection and testing & 369.00 & 3.1538 & 1.03070 & 1.062 & 0.47 & WA \\
\hline Late preparation and delivery of contract document & 343.00 & 2.9316 & 1.03162 & 1.064 & 0.47 & WA \\
\hline Lack of coordination among the parties & 329.00 & 2.8120 & 1.03334 & 1.068 & 0.47 & WA \\
\hline Slow to issue instruction & 339.00 & 2.8974 & 1.03711 & 1.076 & 0.46 & WA \\
\hline Conflicts among the consultants & 314.00 & 2.6838 & 1.03931 & 1.080 & 0.46 & WA \\
\hline Lack of quality assurance & 313.00 & 2.6752 & 1.04080 & 1.083 & 0.46 & WA \\
\hline Shortage of technical professionals in the organization & 317.00 & 2.7094 & 1.04271 & 1.087 & 0.46 & WA \\
\hline Spoilage/ accident of materials at transit & 275.00 & 2.3504 & 1.04483 & 1.092 & 0.45 & WA \\
\hline Non-compliance to site meeting decision & 309.00 & 2.6410 & 1.04602 & 1.094 & 0.45 & WA \\
\hline Delay to furnish and deliver the site to contractor & 319.00 & 2.7265 & 1.04736 & 1.097 & 0.45 & WA \\
\hline Late site liberation by client & 305.00 & 2.6068 & 1.05010 & 1.103 & 0.45 & WA \\
\hline Incomplete information during designing stage & 349.00 & 2.9829 & 1.05031 & 1.103 & 0.45 & WA \\
\hline Late payment to sub-contractor & 363.00 & 3.1026 & 1.05360 & 1.110 & 0.44 & WA \\
\hline Natural disaster & 308.00 & 2.6325 & 1.05535 & 1.114 & 0.44 & WA \\
\hline Slow inspection by client representative & 333.00 & 2.8462 & 1.05549 & 1.114 & 0.44 & WA \\
\hline Damage of material on site & 319.00 & 2.7265 & 1.05556 & 1.114 & 0.44 & WA \\
\hline Non-release of design due to non-payment & 313.00 & 2.6752 & 1.05723 & 1.118 & 0.44 & WA \\
\hline Inappropriate construction methods & 306.00 & 2.6154 & 1.06549 & 1.135 & 0.43 & WA \\
\hline Poor communication network between the parties & 311.00 & 2.6581 & 1.06805 & 1.141 & 0.43 & WA \\
\hline High labour rate & 344.00 & 2.9402 & 1.06908 & 1.143 & 0.43 & WA \\
\hline Lack of functional equipment for the worker on site & 323.00 & 2.7607 & 1.07198 & 1.149 & 0.43 & WA \\
\hline Poor contract documentation & 347.00 & 2.9658 & 1.07424 & 1.154 & 0.42 & WA \\
\hline Wrong choice of financial institution & 319.00 & 2.7265 & 1.07978 & 1.166 & 0.42 & WA \\
\hline Lack of contractor's administration personnel & 348.00 & 2.9744 & 1.08645 & 1.180 & 0.41 & WA \\
\hline Design errors due to poor knowledge of the project & 327.00 & 2.7949 & 1.08706 & 1.182 & 0.41 & WA \\
\hline Non-conciliation of projects to the specific contract sum & 319.00 & 2.7265 & 1.08774 & 1.183 & 0.41 & WA \\
\hline Unavailability of fund & 443.00 & 3.7863 & 1.09725 & 1.204 & 0.40 & WA \\
\hline Geological problems & 302.00 & 2.5812 & 1.10046 & 1.211 & 0.39 & WA \\
\hline Inadequate schedule and planning & 399.00 & 3.4103 & 1.10761 & 1.227 & 0.39 & WA \\
\hline Inexperience designer. & 310.00 & 2.6496 & 1.10887 & 1.230 & 0.39 & WA \\
\hline Unreasonable project time frame & 352.00 & 3.0085 & 1.11026 & 1.233 & 0.38 & WA \\
\hline Unrealistic contract duration imposed by client & 326.00 & 2.7863 & 1.11285 & 1.238 & 0.38 & WA \\
\hline Epidemics outbreak & 279.00 & 2.3846 & 1.11298 & 1.239 & 0.38 & WA \\
\hline Delayed payment for completed work & 421.00 & 3.5983 & 1.11463 & 1.242 & 0.38 & WA \\
\hline Rework due to errors & 337.00 & 2.8803 & 1.11543 & 1.244 & 0.38 & WA \\
\hline Manufacturer defects & 289.00 & 2.4701 & 1.11859 & 1.251 & 0.37 & WA \\
\hline Wastage of materials on site due to rework & 313.00 & 2.6752 & 1.12057 & 1.256 & 0.37 & WA \\
\hline Ambiguous specification of materials & 306.00 & 2.6154 & 1.12070 & 1.256 & 0.37 & WA \\
\hline Instabilities in political system & 420.00 & 3.5897 & 1.12306 & 1.261 & 0.37 & WA \\
\hline
\end{tabular}




\begin{tabular}{|c|c|c|c|c|c|c|}
\hline Factors Impacting Delay of Road Projects & Sum & Mean & $\begin{array}{c}\text { Std. } \\
\text { Deviation }\end{array}$ & Variance & RWG & Decision \\
\hline $\begin{array}{l}\text { Lack of knowledge on the type of contract and award } \\
\text { procedure }\end{array}$ & 316.00 & 2.7009 & 1.12392 & 1.263 & 0.37 & WA \\
\hline Lack of competent and experienced personnel & 343.00 & 2.9316 & 1.12745 & 1.271 & 0.36 & WA \\
\hline $\begin{array}{l}\text { Unavailability of complete design and drawings at the } \\
\text { commencement of the project }\end{array}$ & 343.00 & 2.9316 & 1.12745 & 1.271 & 0.36 & WA \\
\hline Irregular cash flow & 401.00 & 3.4274 & 1.13195 & 1.281 & 0.36 & WA \\
\hline Wrong data provided by the client & 313.00 & 2.6752 & 1.13585 & 1.290 & 0.35 & WA \\
\hline Lack of monitoring, supervision, and control of the project & 362.00 & 3.0940 & 1.13702 & 1.293 & 0.35 & WA \\
\hline Scope and complexity of project & 374.00 & 3.1966 & 1.13896 & 1.297 & 0.35 & WA \\
\hline Delay in handing over site to contractor & 349.00 & 2.9829 & 1.15208 & 1.327 & 0.34 & WA \\
\hline Improper site investigation and understanding of project & 381.00 & 3.2564 & 1.15336 & 1.330 & 0.33 & WA \\
\hline Inadequate experience & 337.00 & 2.8803 & 1.15342 & 1.330 & 0.33 & WA \\
\hline Discrepancies between specification and design & 358.00 & 3.0598 & 1.15438 & 1.333 & 0.33 & WA \\
\hline Demand for huge compensation & 415.00 & 3.5470 & 1.15591 & 1.336 & 0.33 & WA \\
\hline Constraint imposed by end-users & 384.00 & 3.2821 & 1.15852 & 1.342 & 0.33 & WA \\
\hline Inadequate quality control & 370.00 & 3.1624 & 1.15935 & 1.344 & 0.33 & WA \\
\hline Delay and non- payment of compensation & 427.00 & 3.6496 & 1.16202 & 1.350 & 0.32 & WA \\
\hline Traffic restriction & 285.00 & 2.4359 & 1.16252 & 1.351 & 0.32 & WA \\
\hline Conflict among the designed team & 309.00 & 2.6410 & 1.16309 & 1.353 & 0.32 & WA \\
\hline Community policy & 394.00 & 3.3675 & 1.16411 & 1.355 & 0.32 & WA \\
\hline Social and cultural problems & 350.00 & 2.9915 & 1.17073 & 1.371 & 0.31 & WA \\
\hline Incompetent site management & 373.00 & 3.1880 & 1.17394 & 1.378 & 0.31 & WA \\
\hline Increase in fuel prices & 387.00 & 3.3077 & 1.17782 & 1.387 & 0.31 & WA \\
\hline Community leaders interest & 392.00 & 3.3504 & 1.18406 & 1.402 & 0.30 & LA \\
\hline Lack of incentive for the contractor for finishing ahead of time & 320.00 & 2.7350 & 1.19188 & 1.421 & 0.29 & LA \\
\hline Misappropriation of the projects fund & 379.00 & 3.2393 & 1.19373 & 1.425 & 0.29 & LA \\
\hline Lack of community bye-in & 337.00 & 2.8803 & 1.19743 & 1.434 & 0.28 & LA \\
\hline Lack of programme of work & 366.00 & 3.1282 & 1.20013 & 1.440 & 0.28 & LA \\
\hline Unstable soil condition & 348.00 & 2.9744 & 1.20674 & 1.456 & 0.27 & LA \\
\hline Excessive bureaucracy & 366.00 & 3.1282 & 1.21441 & 1.475 & 0.26 & LA \\
\hline Change in government & 438.00 & 3.7436 & 1.22583 & 1.503 & 0.25 & LA \\
\hline Changes in polices & 418.00 & 3.5726 & 1.22697 & 1.505 & 0.25 & LA \\
\hline Lack of interim payment & 422.00 & 3.6068 & 1.23146 & 1.517 & 0.24 & LA \\
\hline Inadequate site investigation prior to design and drawing & 350.00 & 2.9915 & 1.23523 & 1.526 & 0.24 & LA \\
\hline Lack of understanding of contract documents & 347.00 & 2.9658 & 1.25211 & 1.568 & 0.22 & LA \\
\hline Communal crises & 391.00 & 3.3419 & 1.25370 & 1.572 & 0.21 & LA \\
\hline Poor judicial system for dispute resolution & 322.00 & 2.7521 & 1.26563 & 1.602 & 0.20 & LA \\
\hline Difficulty in assessing credit facilities & 360.00 & 3.0769 & 1.26732 & 1.606 & 0.20 & LA \\
\hline Delay in interim payment & 444.00 & 3.7949 & 1.27670 & 1.630 & 0.19 & LA \\
\hline Delay in construction permit approval & 316.00 & 2.7009 & 1.28160 & 1.642 & 0.18 & LA \\
\hline Bad weather condition & 374.00 & 3.1966 & 1.28814 & 1.659 & 0.17 & LA \\
\hline Unavailability of specified materials & 339.00 & 2.8974 & 1.28911 & 1.662 & 0.17 & $\mathrm{LA}$ \\
\hline Delay in settlement of claims for extra work & 383.00 & 3.2735 & 1.32368 & 1.752 & 0.12 & LA \\
\hline Poor funding & 420.00 & 3.5897 & 1.32713 & 1.761 & 0.12 & LA \\
\hline No penalty to project defaulters & 306.00 & 2.6154 & 1.40102 & 1.963 & 0.02 & LA \\
\hline Militancy & 387.00 & 3.3077 & 1.40480 & 1.973 & 0.01 & LA \\
\hline War, rebellion, conflict and riot & 392.00 & 3.3504 & 1.46403 & 2.143 & -0.07 & LA \\
\hline Thefts and vandalism & 378.00 & 3.2308 & 1.49934 & 2.248 & -0.12 & LA \\
\hline The kidnapping of an expatriate worker & 337.00 & 2.8803 & 1.53781 & 2.365 & -0.18 & LA \\
\hline Poor contract management & 416.00 & 3.5556 & 3.92042 & 15.370 & -6.68 & LA \\
\hline
\end{tabular}




\section{Appendix 4}

Calculation of Predicted Probability Procedure in the Cases Employed for Model Validation

\begin{tabular}{|c|c|c|c|c|c|c|c|c|c|c|c|c|c|c|c|c|c|c|}
\hline Case & & $\alpha$ & $\beta 1$ & $\beta 2$ & $\beta 3$ & $\beta 4$ & $\beta 5$ & $\beta 6$ & $\beta 7$ & p8 & $\beta 9$ & $\beta 10$ & $\beta 11$ & $\beta($ total) & {$[\alpha-\beta$ (total)] } & $e^{-(\alpha-\beta}$ & $\frac{1}{1+e^{-(\alpha-\beta)}}$ & \begin{tabular}{|l} 
Predicted \\
Probability
\end{tabular} \\
\hline \multirow{5}{*}{1} & $\mathrm{P}(\mathrm{Y} \leq 1)$ & -6.024 & 1.225 & -1.082 & 2.097 & 1.665 & 2.529 & -1.522 & -0.741 & -1.858 & -1.551 & -0.850 & -0.388 & -0.476 & -5.548 & 256.709 & 0.004 & 0.004 \\
\hline & $\mathrm{P}(\mathrm{Y} \leq 2)$ & -4.484 & 1.225 & -1.082 & 2.097 & 1.665 & 2.529 & -1.522 & -0.741 & -1.858 & -1.551 & -0.850 & -0.388 & -0.476 & -4.008 & 55.015 & 0.018 & 0.014 \\
\hline & $\mathrm{P}(\mathrm{Y} \leq 3)$ & -2.854 & 1.225 & -1.082 & 2.097 & 1.665 & 2.529 & -1.522 & -0.741 & -1.858 & -1.551 & -0.850 & -0.388 & -0.476 & -2.378 & 10.780 & 0.085 & 0.067 \\
\hline & $\mathrm{P}(\mathrm{Y} \leq 4)$ & -0.502 & 1.225 & -1.082 & 2.097 & 1.665 & 2.529 & -1.522 & -0.741 & -1.858 & -1.551 & -0.850 & -0.388 & -0.476 & -0.025 & 1.026 & 0.494 & 0.409 \\
\hline & $\mathrm{P}(\mathrm{Y} \leq 5)$ & & & & & & & & & & & & & & & & & 0.506 \\
\hline \multirow{5}{*}{2} & $\mathrm{P}(\mathrm{Y} \leq 1)$ & -6.024 & 0.817 & -0.722 & 2.097 & 1.110 & 1.686 & -1.015 & -1.482 & -1.858 & -1.939 & -0.850 & -0.388 & -3.481 & -3.481 & 2.495 & 0.030 & 0.030 \\
\hline & $\mathrm{P}(\mathrm{Y} \leq 2)$ & -4.484 & 0.817 & -0.722 & 2.097 & 1.110 & 1.686 & -1.015 & -1.482 & -1.858 & -1.939 & -0.850 & -0.388 & -1.941 & -1.941 & 6.964 & 0.126 & 0.096 \\
\hline & $\mathrm{P}(\mathrm{Y} \leq 3)$ & -2.854 & 0.817 & -0.722 & 2.097 & 1.110 & 1.686 & -1.015 & -1.482 & -1.858 & -1.939 & -0.850 & -0.388 & -0.311 & -0.311 & 1.365 & 0.423 & 0.297 \\
\hline & $\mathrm{P}(\mathrm{Y} \leq 4)$ & -0.502 & 0.817 & -0.722 & 2.097 & 1.110 & 1.686 & -1.015 & -1.482 & -1.858 & -1.939 & -0.850 & -0.388 & 2.041 & 2.041 & 0.130 & 0.885 & 0.462 \\
\hline & $\mathrm{P}(\mathrm{Y} \leq 5)$ & & & & & & & & & & & & & & & & & 15 \\
\hline \multirow{5}{*}{3} & $\mathrm{P}(\mathrm{Y} \leq 1)$ & -6.024 & 1.225 & -1.082 & 2.097 & 1.665 & 1.686 & -1.522 & -1.111 & -1.858 & -1.163 & -0.850 & -0.388 & -4.722 & -4.722 & 112.436 & 0.009 & 0.009 \\
\hline & $\mathrm{P}(\mathrm{Y} \leq 2)$ & -4.484 & 1.225 & -1.082 & 2.097 & 1.665 & 1.686 & -1.522 & -1.111 & -1.858 & -1.163 & -0.850 & -0.388 & -3.182 & 3.182 & 24.096 & 0.040 & .031 \\
\hline & $\mathrm{P}(\mathrm{Y} \leq 3)$ & -2.854 & 1.225 & -1.082 & 2.097 & 1.665 & 1.686 & -1.522 & -1.111 & -1.858 & -1.163 & -0.850 & -0.388 & -1.552 & -1.552 & 4.721 & 0.175 & 0.135 \\
\hline & $\mathrm{P}(\mathrm{Y} \leq 4)$ & -0.502 & 1.225 & -1.082 & 2.097 & 1.665 & 1.686 & -1.522 & -1.111 & -1.858 & -1.163 & -0.850 & -0.388 & 0.800 & 0.800 & 0.449 & 0.690 & 1.515 \\
\hline & $\mathrm{P}(\mathrm{Y} \leq 5)$ & & & & & & & & & & & & & & & & & 31 \\
\hline \multirow{5}{*}{4} & $\mathrm{P}(\mathrm{Y} \leq 1)$ & -6.024 & 1.225 & -0.722 & 2.097 & 1.110 & 1.686 & -1.015 & -0.741 & -0.929 & -1.551 & -0.425 & -0.388 & -6.372 & -6.372 & 585.312 & 0.002 & 0.000 \\
\hline & $\mathrm{P}(\mathrm{Y} \leq 2)$ & -4.484 & 1.225 & -0.722 & 2.097 & 1.110 & 1.686 & -1.015 & -0.741 & -0.929 & -1.551 & -0.425 & -0.388 & \begin{tabular}{|l|} 
\\
\end{tabular} & -4.832 & 125.438 & 0.008 & 0.008 \\
\hline & $\mathrm{P}(\mathrm{Y} \leq 3)$ & -2.854 & 1.225 & -0.722 & 2.097 & 1.110 & 1.686 & -1.015 & -0.741 & -0.929 & -1.551 & -0.425 & -0.388 & \begin{tabular}{|l|} 
\\
\end{tabular} & -3.202 & 24.579 & 0.039 & 0.031 \\
\hline & $\mathrm{P}(\mathrm{Y} \leq 4)$ & -0.502 & 1.225 & -0.722 & 2.097 & 1.110 & 1.686 & -1.015 & -0.741 & -0.929 & -1.551 & -0.425 & -0.388 & \begin{tabular}{|l} 
\\
\end{tabular} & -0.850 & 2.339 & 0.300 & 0.261 \\
\hline & $\mathrm{P}(\mathrm{Y} \leq 5)$ & & & & & & & & & & & & & & & & & 0.700 \\
\hline \multirow{5}{*}{5} & $\mathrm{P}(\mathrm{Y} \leq 1)$ & -6.024 & 1.634 & -1.082 & 2.097 & 0.555 & 2.529 & -1.015 & -0.370 & -0.929 & -1.939 & -0.850 & -0.388 & \begin{tabular}{|l|} 
\\
\end{tabular} & -6.266 & 526.206 & 0.002 & 0.002 \\
\hline & $\mathrm{P}(\mathrm{Y} \leq 2)$ & -4.484 & 1.634 & -1.082 & 2.097 & 0.555 & 2.529 & -1.015 & -0.370 & -0.929 & -1.939 & -0.850 & -0.388 & -4.725 & -4.725 & 112.772 & 0.009 & 0.007 \\
\hline & $\mathrm{P}(\mathrm{Y} \leq 3)$ & -2.854 & 1.634 & -1.082 & 2.097 & 0.555 & 2.529 & -1.015 & -0.370 & -0.929 & -1.939 & -0.850 & -0.388 & -3.095 & -3.095 & 22.097 & 0.043 & 0.034 \\
\hline & $\mathrm{P}(\mathrm{Y} \leq 4)$ & -0.502 & 1.634 & -1.082 & 2.097 & 0.555 & 2.529 & -1.015 & -0.370 & -0.929 & -1.939 & -0.850 & -0.388 & \begin{tabular}{|l|l|} 
& -0.743 \\
\end{tabular} & -0.743 & 2.102 & 0.322 & 0.279 \\
\hline & $\mathrm{P}(\mathrm{Y} \leq 5)$ & & & & & & & & & & & & & & & & & 0.678 \\
\hline
\end{tabular}

